\title{
Parâmetros sanguíneos, hepáticos e ruminais de ovinos alimentados com dietas com farelo de mamona destoxificado
}

\author{
Daniel Ribeiro Menezes( ${ }^{(1)}$, Roberto Germano Costa(2), Gherman Garcia Leal de Araújo(3), \\ Luiz Gustavo Ribeiro Pereira(4), Pablo Teixeira Leal de Oliveira( ${ }^{(5)}$, Aldrin Ederson Vila Nova Silva(1), \\ Tadeu Vinhas Voltolini( ${ }^{(3)}$ e Salete Alves de Moraes $^{(3)}$
}

(1)Universidade Federal do Vale do São Francisco, Centro de Ciências Agrárias, Rodovia BR 407, 12, Lote 543, Projeto de Irrigação Nilo Coelho, CEP 56300-000 Petrolina, PE. E-mail: daniel.menezes@univasf.edu.br, aldrin.ederson@univasf.edu.br(2)Universidade Federal da Paraíba, Departamento de Agropecuária, Campus IV, CEP 58400-000 Bananeiras, PB. E-mail: betogermano@hotmail.com ${ }^{(3)}$ Embrapa Semiárido, BR 428, Km 152, Zona Rural, CEP 56302-970 Petrolina, PE. E-mail: ggla@cpatsa.embrapa.br, tadeu.voltolini@cpatsa.embrapa.br, salete.moraes@cpatsa.embrapa.br ${ }^{(4)}$ Embrapa Gado de Leite, Rua Eugênio do Nascimento, № 610, CEP $36038-330$ Juiz de Fora, MG. E-mail: luiz.gustavo@cnpgl.embrapa.br ${ }^{(5)}$ Instituto Federal do Sertão Pernambucano, Rodovia BR 235, Km 22, CEP 56300-000 Petrolina, PE. E-mail: pablo.leal@ifsertao-pe.edu.br.

Resumo - O objetivo deste trabalho foi avaliar os parâmetros sanguíneos, hepáticos e ruminais, bem como caracterizar e quantificar a população de protozoários ciliados, no rúmen de ovinos alimentados com dietas com farelo de mamona destoxificada (FM). Foram utilizados 32 ovinos, para a avaliação dos parâmetros sanguíneos e hepáticos, e quatro ovinos adultos fistulados no rúmen, para a avaliação dos parâmetros ruminais. A dieta controle foi composta por feno de capim-buffel, milho em grão moído, ureia e farelo de soja (FS). Nos tratamentos, o FS foi substituído parcialmente pelo FM a 15, 30 e 45\% no concentrado. Não houve diferença, entre os tratamentos, quanto aos teores de ureia no soro, cuja média foi de $666,0 \mathrm{mg} \mathrm{L}^{-1}$. Não houve diferença entre as dietas quanto à glicose, ao aspartato aminotranferase e à alanina aminotransferase, que tiveram média de 690,3 $\mathrm{mg} \mathrm{L}^{-1}, 127,4 \mathrm{UI} \mathrm{L}^{-1}$ e $16,9 \mathrm{UI} \mathrm{L}^{-1}$, respectivamente. Os valores de nitrogênio amoniacal e pH apresentaram padrão linear crescente com a substituição do FS pelo FM. O gênero Entodinium foi o mais frequente em todos os tratamentos e obteve média geral de 76,4\% do total de protozoários; o tratamento sem inclusão do FM obteve a maior percentagem deste gênero entre os tratamentos. A dieta com substituição de $45 \%$ do farelo de soja pelo de mamona destoxificado favorece o ambiente ruminal.

Termos para indexação: Ricinus communis, ciliados, metabolismo, microbiota, rúmen.

\section{Blood, liver and rumen parameters of sheep fed diets containing detoxified castor bean meal}

\begin{abstract}
The objective of this work was to evaluate the blood, liver and rumen parameters, as well as to characterize and quantify the population of ciliated protozoa in the rumen of sheep fed diets with detoxified castor bean meal (DCBM). Thirty-two lambs were used, for the evaluation of blood and liver parameters, and four rumen-cannulated adult sheep were used to determine rumen parameters. The control diet was composed by buffel grass hay, ground corn grain, urea and soybean meal (SBM). In the treatments, SBM was partially replaced by DCBM at 15,30 and $45 \%$ in the concentrate. There was no significant difference, among treatments, for the serum-urea contents whose mean value was $666.0 \mathrm{mg} \mathrm{L}^{-1}$. There was no significant difference, among diets, for glucose, aspartate aminotransferase and alanine aminotransferase, which had mean values of $690.3 \mathrm{mg} \mathrm{L}^{-1}, 127.4 \mathrm{IUL}^{-1}$ and $16.9 \mathrm{IUL}^{-1}$, respectively. The ammoniacal nitrogen and $\mathrm{pH}$ values had an increasing linear pattern with the replacement of SBM by DCBM. The genus Entodinium was the most frequent in all treatments and showed $76.4 \%$ overall mean of the total protozoa; the treatment without DCBM had the highest percentage of this genus among treatments. The diet substitution above $45 \%$ of soybean meal by the detoxified castor bean meal is favorable to the rumen environment.
\end{abstract}

Index terms: Ricinus communis, ciliates, metabolism, microbiota, rumen.

\section{Introdução}

A mamona (Ricinus communis L.), por apresentar características como adaptabilidade a solos mais arenosos e resistência à seca, é indicada como matéria prima para o biocombustível na região Nordeste do Brasil (Severino, 2005). E a indústria desse produto é responsável por grandes quantidades de resíduos, que causam problemas ambientais e, além disso, representam encargos com estocagem. Assim, há necessidade de um destino adequado e sustentável para tais materiais, para transformá-los em coprodutos, cuja utilização é uma alternativa importante para a nutrição animal. Entretanto, a presença de princípios tóxicos e alergênicos pode dificultar esse uso (Oliveira et al., 2010). 
A ricina é uma proteína encontrada exclusivamente no endosperma das sementes e é mantida na torta e no farelo de mamona, sendo a principal toxina presente (Aslani, 2007). Classificada como um tipo de lecitina, que tem um sítio receptor específico para açúcar ou para uma unidade de oligossacarídeo e outro com atividade enzimática, essa toxina exerce seu mecanismo de toxidez por meio da inativação dos ribossomos (Anandan et al., 2005).

Em células procariontes, a ricina - intacta ou em cadeias isoladas - não mostra efeitos tóxicos, porém polipeptídeos ativos, obtidos a partir da hidrólise da ricina por tripsina, são capazes de inibir a síntese de proteínas de Escherichia coli (Haas-Kohn et al., 1980). Oliveira et al. (2010) observaram o aumento da síntese de proteína microbiana em ovinos, após a destoxificação parcial do farelo de mamona por tratamento alcalino, mas esse efeito, de acordo com os autores, pode ter sido influenciado pelo incremento da ingestão de nutrientes digestíveis.

O objetivo deste trabalho foi avaliar os parâmetros sanguíneos, hepáticos e ruminais, bem como caracterizar e quantificar a população de protozoários ciliados, no rúmen de ovinos alimentados com dietas contendo farelo de mamona destoxificado.

\section{Material e Métodos}

O experimento foi realizado no Setor de Nutrição Animal da Embrapa Semiárido, em Petrolina, PE, entre maio e julho de 2010. Formuladas de acordo com o National Research Council (2007), para a obtenção de ovinos com $30 \mathrm{~kg}$ de peso vivo e ganho de peso diário de $200 \mathrm{~g}$, as dietas experimentais foram compostas por feno de capim-buffel, milho em grão moído, ureia e por farelo de soja (FS), que foi substituído parcialmente pelo farelo de mamona destoxificado (FM) em 15, 30 e $45 \%$, com base na matéria seca do concentrado. O tratamento testemunha não teve inclusão do FM. A proporção volumoso:concentrado utilizada foi de 40:60. As dietas foram fornecidas duas vezes ao dia, às $8 \mathrm{~h}$ e às $16 \mathrm{~h}$, distribuidas em partes iguais.

Foram utilizados 32 ovinos com peso médio de $21,7 \pm 2,6 \mathrm{~kg}$ e idade média de 10 meses, para a avaliação dos parâmetros sanguíneos e hepáticos (ensaio 1), e quatro ovinos fistulados no rúmen, com peso médio de $60,0 \pm 4,7 \mathrm{~kg}$ e idade média de 24 meses, para a avaliação dos parâmetros ruminais (ensaio 2). Todos os animais foram tratados com vermífugos e vacinas antes do início do experimento. O período experimental para o ensaio 1 compreendeu 20 dias, e as coletas foram feitas cinco dias antes do final do período, tendo-se utilizado o delineamento experimental em blocos ao acaso, com oito repetições por tratamento, e o peso inicial como fator dos blocos. Os animais foram confinados em galpão coberto e em gaiolas metabólicas individuais. No ensaio 2, utilizou-se o delineamento experimental em quadrado latino $4 \times 4$, com quatro tratamentos, quatro animais e quatro períodos. O ensaio 2 estendeu-se por 80 dias, e cada período foi dividido em 15 dias de adaptação e cinco dias de coleta de dados.

Nos dois ensaios, água e sal mineral foram ofertados à vontade, e o consumo de alimentos foi quantificado diariamente. Para garantir consumo à vontade aos animais, trabalhou-se com excedentes de aproximadamente $20 \%$ do consumido no dia anterior. O sal mineral utilizado teve como formulação: cálcio, $130 \mathrm{~g}$; fósforo, $75 \mathrm{~g}$; magnésio, $5 \mathrm{~g}$; ferro, $1.500 \mathrm{mg}$; cobalto, $100 \mathrm{mg}$; cobre, $275 \mathrm{mg}$; manganês, $1.000 \mathrm{mg}$; zinco, $2.000 \mathrm{mg}$; iodo, $61 \mathrm{mg}$; selênio, $11 \mathrm{mg}$; enxofre, $14 \mathrm{~g}$; sódio, $151 \mathrm{~g}$; cloro, $245 \mathrm{~g}$; flúor máximo, $175 \mathrm{mg}$.

O FM foi destoxificado com hidróxido de cálcio $\left(\mathrm{Ca}(\mathrm{OH})_{2}\right)$ diluído em água à proporção de $9 \mathrm{~L}$ de água por quilograma de $\mathrm{Ca}(\mathrm{OH})_{2}$. A proporção utilizada foi $60 \mathrm{~g}$ de $\mathrm{Ca}(\mathrm{OH})_{2}$ por quilograma de farelo de mamona. Após o tratamento, o farelo de mamona misturado à solução de hidróxido de cálcio foi acondicionado em tambor de polietileno por 24 horas e, posteriormente, seco ao sol por 12 horas.

Utilizou-se feno de capim-buffel (Cenchrus ciliaris 'Biloela'). A ureia foi adicionada às dietas, para torná-las isoproteicas, na proporção de $0,0,3,0,5$ e $0,7 \%$ de matéria seca (MS), conforme a substituição do farelo de soja pelo farelo de mamona.

Os alimentos e as dietas foram moídos em moinho de faca tipo Willey até atingirem $2 \mathrm{~mm}$ de tamanho. Após esse procedimento, os alimentos e as dietas foram analisados para a determinação da MS, matéria orgânica $(\mathrm{MO})$, proteína bruta $(\mathrm{PB})$, extrato etéreo (EE), lignina (LIG), cinzas (MM) e energia bruta (EB), de acordo com Silva \& Queiroz (2002). A fibra em detergente neutro (FDN) e a fibra em detergente ácido (FDA) foram analisadas de acordo com Van Soest et al. (1991). Os carboidratos totais (CHOT) e os carboidratos não fibrosos (CNF) foram estimados 
de acordo com Sniffen et al. (1992) e Mertens (1997), respectivamente. A composição bromatológica das dietas está apresentada na Tabela 1 .

Calcularam-se os valores de energia digestível (ED) e energia metabolizável (EM) pela técnica direta de determinação de energia com bomba calorimétrica. Para o cálculo de ED e EM, utilizou-se a fórmula de Blaxter \& Clapperton (1965), em que: ED = consumo de $\mathrm{EB}$ - EB das fezes, e a EM = ED - (EB da urina + energia dos gases). A energia dos gases foi representada pela produção de metano, estimada por $\mathrm{Cm}=0,67+$ 0,062D, em que: $\mathrm{Cm}$, produção de metano em kcal por $100 \mathrm{kcal}$ de energia consumida; e $\mathrm{D}$, digestibilidade aparente da EB do alimento.

As colheitas de fluido ruminal (ensaio 2) foram realizadas em cada animal, pelo acesso direto ao rúmen, três horas após a alimentação matinal. Foram obtidos aproximadamente $100 \mathrm{~mL}$ de fluido ruminal (amostra principal), após filtração com auxílio de uma peneira com dupla camada de gaze. Após serem colhidas, as amostras foram acondicionadas em garrafas térmicas previamente aquecidas $\mathrm{a} \pm 39^{\circ} \mathrm{C}$. As análises físicas do fluido ruminal foram realizadas logo após a colheita e caracterizadas pela avaliação física da cor, odor,

Tabela 1. Participação dos ingredientes nas dietas experimentais e composição química das dietas caracterizadas pela substituição parcial do farelo de soja pelo farelo de mamona destoxificado.

\begin{tabular}{|c|c|c|c|c|}
\hline \multirow[t]{2}{*}{ Participação do ingrediente (\%) } & \multicolumn{4}{|c|}{ Nível de substituição (\%) } \\
\hline & 0 & 15 & 30 & 45 \\
\hline Feno de capim buffel & 40,0 & 40,0 & 40,0 & 40,0 \\
\hline Milho em grão moído & 30,0 & 30,0 & 30,0 & 30,0 \\
\hline Farelo de soja & 30,0 & 25,0 & 21,0 & 16,0 \\
\hline Farelo de mamona destoxificado & 0,0 & 4,7 & 8,5 & 13,3 \\
\hline Ureia & 0,0 & 0,3 & 0,5 & 0,7 \\
\hline \multicolumn{5}{|l|}{ Composição (\%) } \\
\hline Matéria seca (\%) & 91,0 & 91,1 & 92,2 & 92,2 \\
\hline Matéria orgânica ${ }^{(1)}$ & 85,1 & 84,7 & 85,5 & 85,2 \\
\hline Matéria mineral $^{(1)}$ & 3,9 & 4,6 & 5,1 & 5,7 \\
\hline Proteína bruta $^{(1)}$ & 20,6 & 20,6 & 20,4 & 20,5 \\
\hline Extrato etéreo $^{(1)}$ & 3,4 & 3,4 & 3,5 & 3,6 \\
\hline Carboidratos totais ${ }^{(1)}$ & 72,1 & 71,4 & 71,0 & 70,2 \\
\hline Carboidratos não fibrosos ${ }^{(1)}$ & 26,6 & 24,6 & 23,9 & 22,4 \\
\hline Fibra em detergente neutro ${ }^{(1)}$ & 45,5 & 46,3 & 47,1 & 47,8 \\
\hline Fibra em detergente ácido ${ }^{(1)}$ & 21,2 & 22,3 & 23,4 & 23,8 \\
\hline Lignina $^{(1)}$ & 3,9 & 5,2 & 6,3 & 7,7 \\
\hline Energia bruta (Mcal kg-1 de MS) & 3,88 & 3,85 & 3,81 & 3,77 \\
\hline Energia digestível (Mcal kg-1 de MS) & 3,32 & 3,21 & 3,19 & 2,95 \\
\hline Energia metabolizável (Mcal kg-1 de MS) & 2,61 & 2,60 & 2,62 & 2,40 \\
\hline
\end{tabular}

consistência, tempo de sedimentação e flotação (TSF). Para a realização do TSF, colocaram-se $10 \mathrm{~mL}$ de fluido ruminal (subamostra) em tubos cônicos Falcon TTP (Transform Tecnologia em Plásticos, Porto Alegre, RS, Brasil), e as amostras foram deixadas em repouso (Borges et al., 2002).

Foram averiguados o $\mathrm{pH}$ e a condutividade (Cond), com potenciômetro e condutivímetro digitais, e a redução do azul de metileno (RAM). A determinação do tempo de redução foi realizada com tubos cônicos Falcon, nos quais se colocaram $9,5 \mathrm{~mL}$ de fluido ruminal e 0,5 $\mathrm{mL}$ de azul de metileno (solução 0,02\%) (Rosenberger, 1993). Para a determinação do $\mathrm{N}$-amoniacal, foi adicionado $1 \mathrm{~mL}$ de ácido sulfúrico 1:1 a $30 \mathrm{~mL}$ de amostra coletada, a qual foi armazenada e congelada, para posterior análise. As concentrações de $\mathrm{N}$-amoniacal, nas amostras do líquido ruminal filtrado, foram determinadas mediante destilação com hidróxido de potássio 2N (Preston, 1995).

Foi obtida subamostra de líquido ruminal, imediatamente após a coleta, e desta procedeu-se às avaliações qualitativas do fluido ruminal, que consistiram da determinação da consistência (líquida ou viscosa), odor (aromático ou intenso) e cor (verde ou verde-pardo), por meio dos órgãos dos sentidos (Diaz González et al., 2000). A determinação da motilidade de protozoários foi realizada por meio de depósito de uma gota do fluido ruminal em uma lâmina coberta com lamínula, previamente aquecida a $37^{\circ} \mathrm{C}$; a gota foi observada em microscópio óptico (40x), e a motilidade foi classificada como normal, hipomotilidade ou hipermotilidade (Barbosa et al., 2003). A relação de protozoários vivos por mortos foi realizada pela técnica modificada de Barbosa et al. (2003), com o depósito de uma gota do fluido ruminal em câmara MacMaster (SEM - Electron Microscopy Sciences, Hatfield, PA, EUA) coberta com lamínula, previamente aquecida a $37^{\circ} \mathrm{C}$, e os protozoários foram contados em microscópio óptico (40x).

A contagem e a diferenciação de protozoários do fluido ruminal foram feitas conforme Dehority (1977); as amostras foram fixadas em igual volume de solução de formaldeído a 18,5\% (Dehority, 1984), após leitura em câmara MacMaster.

O procedimento de coleta de sangue dos 32 animais (ensaio 1) realizou-se por punção da veia jugular, cinco dias antes do final do período experimental, seis horas após a alimentação da manhã, para a análise do teor 
de ureia no soro (TUS) e, antes da alimentação, para os outros parâmetros, por meio de tubos Vacutainer (BD - Becton, Dickinson and Co., Franklin Lakes, NJ, EUA) com capacidade para 4,0 mL. Foram colhidas três amostras de sangue de cada animal, em dois tubos que continham anticoagulante, e em um tubo sem anticoagulante. Um dos tubos com anticoagulante foi direcionado para a dosagem de proteínas totais e hemoglobina, e o outro para a dosagem de ureia. No tubo sem anticoagulante foram analisadas a glicose, a aspartato transaminase (AST), a alanina transaminase (ALT) e o cálcio sérico. Para a dosagem de ureia, o soro foi obtido por centrifugação dos tubos a $3.293 \mathrm{~g}$ por 15 min, identificado e armazenado em minitubos Eppendorf, e congelado para análise. Os parâmetros sanguíneos foram analisados com kits comerciais (Labtest, 1999), com auxílio de procedimentos colorimétricos.

As análises de variância e frequência e os testes de regressão linear e quadrática foram realizados por meio do programa estatístico SAS Institute (2003). Os modelos foram escolhidos com base na significância dos coeficientes de regressão, pelo teste t, a 1 e $5 \%$ de probabilidade.

\section{Resultados e Discussão}

Os teores de ureia no soro (TUS) não apresentaram diferença estatística entre os tratamentos testados (Tabela 2). As dietas com níveis de substituição do FS pelo FM apresentaram TUS médio de $683,0 \mathrm{mg} \mathrm{L}^{-1}$, seis horas após o fornecimento dos alimentos, valor acima do intervalo proposto como ideal para ovinos, que é de 240 até $500 \mathrm{mg} \mathrm{L}^{-1}$ (Diaz González et al., 2000;
Menezes et al., 2006). A dieta sem a participação do FM também apresentou valor médio acima do referenciado. Assim, os valores médios obtidos para TUS, em todos os tratamentos, expressam desequilíbrio na relação energia/proteína. Esse fato pode ser explicado, em parte, pela deficiência em energia consumida pelos animais que, no fígado, incrementaram a neoglicogênese a partir dos aminoácidos, com posterior aumento dos níveis séricos de amônia que é transformada em ureia. Assim, há incremento de ureia circulante, além de gasto energético na metabolização desta no fígado (Huntington \& Archibeque, 1999).

Na Tabela 2, observa-se evidência de que não houve diferença entre as dietas com níveis de substituição do FS pelo FM e a dieta sem inclusão do FM. Quanto à hemoglobina e às proteínas totais, os valores médios observados foram de 121,4 e 73,9 $\mathrm{g} \mathrm{L}^{-1}$, respectivamente. Segundo Pugh (2004), os valores de referência para hemoglobina em ovinos estão no intervalo de 51,0 a $113,0 \mathrm{~g} \mathrm{~L}^{-1}$ e, para proteínas totais, 67,4 e $71,0 \mathrm{~g} \mathrm{~L}^{-1}$. Assim, os valores obtidos no presente trabalho encontram-se acima das referências, o que indica que as dietas testadas disponibilizaram aporte excessivo de proteínas para o metabolismo dos animais.

Quanto à glicose, não houve diferença entre as dietas, que apresentaram valor médio de $690,3 \mathrm{mg} \mathrm{L}^{-1}$ antes da alimentação dos animais e está dentro do intervalo-referência de 500 a $800 \mathrm{mg} \mathrm{L}^{-1}$ para ovinos (Pugh, 2004).

Branco et al. (2004) avaliaram o efeito de fontes de proteína, com diferentes taxas de degradação ruminal, sobre o metabolismo esplâncnico de glicose em ovinos. Esses autores obtiveram valores médios de $691,2 \mathrm{mg} \mathrm{L}^{-1}$, para glicose em dietas com farelo de

Tabela 2. Médias de ureia, hemoglobina, proteína total, glicose, aspartato aminotransferase (AST), alanina aminotransferase (ALT), cálcio, e seus respectivos desvios-padrão, erro-padrão da média (EPM) e efeito (p), em consequência dos níveis de substituição do farelo de soja pelo farelo de mamona destoxificado.

\begin{tabular}{|c|c|c|c|c|c|c|}
\hline \multirow[t]{2}{*}{ Parâmetro } & \multicolumn{4}{|c|}{ Nível de substituição do farelo de soja (\%) } & \multirow[t]{2}{*}{ EPM } & \multirow[t]{2}{*}{$\mathrm{p}$} \\
\hline & 0 & 15 & 30 & 45 & & \\
\hline Ureia $\left(\mathrm{mg} \mathrm{L}^{-1}\right)$ & $720,7 \pm 51,4$ & $660,0 \pm 57,6$ & $768,3 \pm 69,3$ & $620,9 \pm 55,6$ & 10,26 & ns \\
\hline Hemoglobina $\left(\mathrm{g} \mathrm{L}^{-1}\right)$ & $121,7 \pm 8,7$ & $124,2 \pm 14,2$ & $126,6 \pm 16,3$ & $113,2 \pm 23,0$ & 1,65 & ns \\
\hline Proteína total $\left(\mathrm{g} \mathrm{L}^{-1}\right)$ & $73,9 \pm 7,6$ & $73,5 \pm 6,9$ & $72,2 \pm 7,4$ & $75,9 \pm 7,7$ & 0,73 & ns \\
\hline Glicose $\left(\mathrm{mg} \mathrm{L}^{-1}\right)$ & $685,7 \pm 85,6$ & $706,0 \pm 89,8$ & $697,4 \pm 111$ & $672,4 \pm 54,6$ & 8,55 & ns \\
\hline AST (UI L-1) & $144,9 \pm 22,0$ & $129,7 \pm 31,2$ & $117,9 \pm 16,2$ & $117,1 \pm 22,8$ & 23,18 & ns \\
\hline ALT (UI L-1) & $17,0 \pm 3,22$ & $17,6 \pm 2,51$ & $16,9 \pm 2,09$ & $16,2 \pm 2,02$ & 2,45 & ns \\
\hline Cálcio (mg L-1) & $98,0 \pm 6,1$ & $104,0 \pm 3,2$ & $104,0 \pm 4,0$ & $105,0 \pm 5,5$ & 0,49 & ns \\
\hline
\end{tabular}

ns Não significativo. 
soja como fonte proteica, e de $678,6 \mathrm{mg} \mathrm{L}^{-1} \mathrm{em}$ dietas com farelo de glúten. Os mesmos autores verificaram que não houve interferência da fonte proteica sobre os teores de glicose circulante. Os valores obtidos no presente trabalho se assemelham aos desses autores (Tabela 2).

Não foram observadas alterações nas concentrações das enzimas AST e ALT com a substituição parcial do FS pelo FM, e os valores médios observados foram 127,4 e 16,9 UI L ${ }^{-1}$, respectivamente. De acordo com Radostits et al. (2002), animais sadios apresentam intervalos de 60-280 e 22-28 UI L-1 quanto à AST e ALT, respectivamente. Valores acima destes indicam possível degeneração das células hepáticas. Batista et al. (2009) testaram enzimas hepáticas em 371 ovinos sadios e concluíram que o valor médio para AST deve ser de no máximo 260,2 UI L ${ }^{-1}$, que pode ser utilizado como valor normal para ovinos na região semiárida do Brasil.

A substituição parcial do FS pelo FM não influenciou os níveis séricos de cálcio, que apresentaram valor médio de $103,0 \mathrm{mg} \mathrm{L}^{-1}$. No presente trabalho, o farelo de mamona foi destoxificado com $60 \mathrm{~g} \mathrm{~kg}^{-1} \mathrm{de}$ hidróxido de cálcio, o que poderia influenciar os teores sistêmicos de cálcio. Os valores obtidos encontram-se no intervalo de referência para cálcio sérico - de 76,0 a 128,0 $\mathrm{mg} \mathrm{L}^{-1}$ - em animais sadios (Kaneko et al., 1997; Batista et al., 2009), e não mostram interferência do processo de destoxificação sobre o metabolismo desse mineral nos animais.

Por meio da avaliação dos parâmetros qualitativos do líquido ruminal, nota-se que, em todas as dietas, foi observada a cor verde-oliva, que indica a normalidade do líquido (Tabela 3). Na dieta sem inclusão de FM, $75 \%$ das observações mostraram pelo odor, classificado

Tabela 3. Distribuição (\%) das ocorrências dos parâmetros qualitativos do fluido ruminal, em consequência dos níveis de substituição do farelo de soja pelo farelo de mamona destoxificado.

\begin{tabular}{lcccc}
\hline Parâmetro & \multicolumn{4}{c}{ Nível de substituição (\%) } \\
\cline { 2 - 5 } & 0 & 15 & 30 & 45 \\
\hline Cor $^{(1)}$ & $100 / 0$ & $100 / 0$ & $100 / 0$ & $100 / 0$ \\
Odor $^{(2)}$ & $75 / 25$ & $100 / 0$ & $100 / 0$ & $100 / 0$ \\
Viscosidade $^{(3)}$ & $100 / 0$ & $100 / 0$ & $100 / 0$ & $100 / 0$ \\
Motilidade $^{(4)}$ & $25 / 75 / 0$ & $25 / 50 / 25$ & $0 / 75 / 25$ & $0 / 75 / 25$ \\
Vivos/mortos & $73 / 27$ & $81 / 19$ & $83 / 17$ & $82 / 18$ \\
\hline
\end{tabular}

${ }^{(1)}$ Verde-oliva/verde-parda, (2)aromático/intenso, ${ }^{(3)}$ viscoso/líquido, (4)hipo/ normal/hiper. como aromático, a presença de compostos voláteis gerados fisiologicamente na fermentação ruminal. De acordo com Radostits et al. (2002), o odor de mofo ou podre, em geral, indica putrefação de proteína, e um cheiro desagradável e intenso é indício de formação excessiva de ácido lático decorrente de sobrecarga por grãos e consequente redução do $\mathrm{pH}$ ruminal. $\mathrm{O} \mathrm{pH}$ evidenciado na dieta sem inclusão do FM foi o mais ácido entre as dietas com substituições parciais do FS pelo FM (Tabela 4) e corroborou a avaliação qualitativa do odor do líquido ruminal.

A viscosidade foi de $100 \%$ em todos os tratamentos (Tabela 3), e o de 15\% de substituição do FS pelo FM apresentou motilidade normal dos protozoários de 50\% e se diferenciou dos outros tratamentos. Esse fato pode ser explicado pela possível menor disponibilidade de substrato para as populações de protozoários, o que alterou suas atividades.

Foi observado incremento na percentagem de protozoários vivos com a substituição do FS pelo FM. Esse fato pode ser explicado pelo aumento do $\mathrm{pH}$ ruminal que se tornou próximo do ideal para a sobrevivência dos protozoários. Estes se mostram sensíveis a modificações do $\mathrm{pH}$, principalmente abaixo da normalidade (Franzolin \& Dehority, 1996).

Não houve diferença para as variáveis bioquímicas: redução do azul de metileno, tempo de sedimentação e flotação e condutividade. Os valores médios foram 1'18", 5'40" min e 5,24 mV, respectivamente. De acordo com Radostits et al. (2002), em caso de digestão muito ativa, ocorre descoloração do azul de metileno em 3 min, e quando a descoloração requer mais tempo, o

Tabela 4. Médias da redução do azul de metileno (RAM) e tempo de sedimentação e flotação (TSF), médias do nitrogênio amoniacal $\left(\mathrm{N} \mathrm{NH}_{3}\right.$ ), condutividade (Cond) e potencial hidrogeniônico $(\mathrm{pH})$ com os respectivos desviopadrão, erro-padrão da média (EPM) e efeito $(\mathrm{P})$, em razão dos níveis de substituição do farelo de soja pelo farelo de mamona destoxificado.

\begin{tabular}{|c|c|c|c|c|c|c|}
\hline \multirow[t]{2}{*}{ Parâmetro } & \multicolumn{4}{|c|}{ Nível de substituição (\%) } & \multirow[t]{2}{*}{$\mathrm{EPM}^{(1)}$} & \multirow[t]{2}{*}{$\mathrm{p}$} \\
\hline & 0 & 15 & 30 & 45 & & \\
\hline RAM (min) & 1'40" & 1'08', & 1'09" & 1'15" & 6,072 & ns \\
\hline TSF (min) & $5 ' 25^{\prime \prime}$ & $5,50 ”$ & $5 ' 52 ”$ & $54^{\prime \prime}$ & 12,38 & ns \\
\hline N NH3 $\left(\mathrm{mg} \mathrm{L}^{-1}\right)$ & $26,6 \pm 11,3$ & $44,6 \pm 15,0$ & $42,0 \pm 12,0$ & $50,5 \pm 10,0$ & 1,824 & $*(2)$ \\
\hline Cond (mV) & $4,85 \pm 0,68$ & $5,79 \pm 0,59$ & $5,15 \pm 0,58$ & $5,16 \pm 0,79$ & 0,695 & ns \\
\hline $\mathrm{pH}$ & $5,94 \pm 0,27$ & $6,11 \pm 0,30$ & $6,11 \pm 0,30$ & $6,18 \pm 0,30$ & 0,336 & $* *(3)$ \\
\hline
\end{tabular}

${ }^{(1)}$ Calculado em segundos para RAM e TSF. (2)Equação de regressão: $y=30,56+0,461 x ; R^{2}=0,75 .{ }^{(3)}$ Equação de regressão: $y=5,977+0,0048 x$; $\mathrm{R}^{2}=0,45$. ${ }^{\mathrm{n}}$ Não significativo. ${ }^{*} \mathrm{e} * *$ Significativo a 5 e $1 \%$ de probabilidade. 
indício é de que a atividade no ambiente ruminal está diminuída. No presente trabalho, a redução ocorreu antes de 2 min em todos os tratamentos, possivelmente pelo nível de concentrado utilizado $(60 \%)$, que levou à maior atividade ruminal.

O tempo de sedimentação e flotação normal esperado é de 4 a 8 min, e modificações nesse tempo podem estar relacionadas a anormalidades como ausência de flutuação em acidose (Radostits et al., 2002). Na Tabela 4, observa-se que os valores obtidos em todos os tratamentos encontram-se na faixa de variação normal.

Os valores de nitrogênio amoniacal $\left(\mathrm{N}^{-\mathrm{NH}_{3}}\right)$ e $\mathrm{pH}$ apresentaram comportamento linear crescente com a substituição do FS pelo farelo de mamona. A cada 15\% de substituição do FS pelo FM, houve incremento de 7,0 $\mathrm{mg} \mathrm{L}^{-1}$ e 0,07 de unidades de $\mathrm{pH}$, respectivamente. A elevação do $\mathrm{pH}$ ruminal, com a participação do FM nas dietas, pode ser explicada pela utilização do hidróxido de cálcio, uma base alcalina com pKa 12,8, na destoxificação do FM. Outra explicação é o aumento dos teores de $\mathrm{N}-\mathrm{NH}_{3}$, que podem ter levado ao incremento no $\mathrm{pH}$ ruminal.

Os valores de $\mathrm{N}^{-\mathrm{NH}_{3}}$ na substituição de $45 \%$ do FS pelo FM, mostram-se acima do valor de $50 \mathrm{mg} \mathrm{L}^{-1}$, citados por Satter \& Slyter (1974) como mínimo para a ocorrência da fermentação microbiana. Entretanto, de acordo com Leng (1990), para ruminantes em condições tropicais, são necessários mínimos de 100 e $200 \mathrm{mg} \mathrm{L}^{-1}$ para a maximização da digestão e do consumo de MS, respectivamente.

Assim, o comportamento do $\mathrm{N}_{-} \mathrm{NH}_{3}$ pode ser explicado pela possível degradação da fração proteica das dietas, pelas bactérias ruminais, para obtenção de nitrogênio amoniacal e energia (Huntington \&
Archibeque, 1999). Ao mesmo tempo em que ocorreu esta degradação, grande parte do $\mathrm{N}-\mathrm{NH}_{3}$ presente no rúmen, possivelmente, foi mobilizado como proteína microbiana. Entretanto, na substituição de $45 \%$ do FS pelo FM, houve um desequilíbrio nessa dinâmica entre energia e proteína, no ambiente ruminal, que levou ao incremento de $\mathrm{N}^{-\mathrm{NH}_{3}}$ em relação à taxa de utilização do FM para síntese de proteína microbiana.

O total de protozoários e os gêneros Entodinium e Epidinium apresentaram comportamento linear crescente com a substituição do FS pelo FM, e a cada $15 \%$ de inclusão, foram obtidos incrementos de $3,7 \times 10^{4}, 2,6 \times 10^{4}$, e $0,86 \times 10^{4} \mathrm{~mL}$ de líquido ruminal, respectivamente. Os gêneros Diplodinium, Isotricha e Eudiplodinium não foram influenciados pela substituição do FS pelo FM e obtiveram médias de $0,9 \times 10^{4}, 0,75 \times 10^{4}$, e $0,075 \times 10^{4} \mathrm{~mL}$, respectivamente.

O gênero Entodinium foi o mais frequente em todos os tratamentos, e o tratamento sem inclusão do FM obteve maior percentagem deste gênero (Tabela 5). A quantidade e a diversidade de protozoários ciliados no rúmen são influenciadas pela natureza das dietas ingeridas, pelo $\mathrm{pH}$ do ambiente ruminal e pelas relações que se estabelecem entre as populações de protozoários e a população bacteriana. Entre esses fatores, as dietas são citadas como o principal modificador do perfil das comunidades de protozoários no ambiente ruminal (Arcuri et al., 2006; Martinele et al., 2008).

Os protozoários do gênero Entodinium têm sua atividade aumentada e, com isso, estão em maior percentagem quando expostos a dietas ricas em grãos (Franzolin \& Dehority, 1996). No atual experimento, foi utilizado $60 \%$ de concentrado, fato que corrobora os mencionados na literatura. Martinele et al. (2008)

Tabela 5. Médias \pm desvio-padrão $\left(\times 10^{4} \mathrm{~mL}^{-1}\right)$ dos principais gêneros de ciliados e do total de protozoários do líquido ruminal, composição relativa (CR), e efeito (p), em consequência dos níveis de substituição de 15, 30 e $45 \%$ do farelo de soja pelo farelo de mamona destoxificado.

\begin{tabular}{|c|c|c|c|c|c|c|c|c|c|}
\hline \multirow[t]{2}{*}{ Gênero } & \multicolumn{2}{|c|}{$0(\%)$} & \multicolumn{2}{|c|}{$15(\%)$} & \multicolumn{2}{|c|}{$30(\%)$} & \multicolumn{2}{|c|}{$45(\%)$} & \multirow[t]{2}{*}{$\mathrm{p}$} \\
\hline & Média & CR (\%) & Média & CR (\%) & Média & CR (\%) & Média & CR (\%) & \\
\hline Entodinium & $5,5 \pm 5,5$ & 80,9 & $10,3 \pm 8,2$ & 78,6 & $11,3 \pm 6,4$ & 69,4 & $13,8 \pm 5,8$ & 76,7 & $*(1)$ \\
\hline Diplodinium & $0,5 \pm 2,4$ & 7,3 & $0,8 \pm 1,3$ & 6,2 & $2,3 \pm 2,9$ & 14,4 & $0,0 \pm 0,0$ & 0,0 & ns \\
\hline Epidinium & $0,8 \pm 2,1$ & 11,8 & $1,0 \pm 1,6$ & 7,6 & $1,5 \pm 2,8$ & 8,1 & $3,2 \pm 7,73$ & 17,7 & $*(2)$ \\
\hline Isotricha & $0,0 \pm 0,0$ & 0,0 & $1,0 \pm 0,7$ & 7,6 & $1,0 \pm 0,9$ & 6,3 & $1,0 \pm 0,98$ & 5,6 & ns \\
\hline Eudiplodinium & $0,0 \pm 0,0$ & 0,0 & $0,0 \pm 0,0$ & 0,0 & $0,3 \pm 1,8$ & 1,8 & $0,0 \pm 0,00$ & 0,0 & ns \\
\hline Total & $6,8 \pm 7,7$ & 100 & $13,1 \pm 7,7$ & 100 & $16,0 \pm 7,7$ & 100 & $18,0 \pm 7,7$ & 100 & $*(3)$ \\
\hline
\end{tabular}

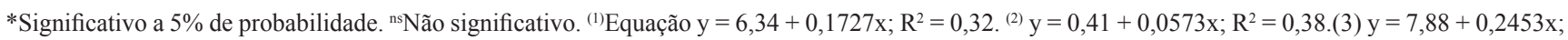
$\mathrm{R}^{2}=0,40$. 
testaram dietas sem e com adições de 20 e $40 \%$ de concentrado e obtiveram aumento na contagem de protozoários do gênero Entodinium. No nível de $40 \%$ de concentrado, esses autores obtiveram valor absoluto de $42 \times 10^{4} \mathrm{~mL}$, o que representa $79 \%$ do total de protozoários.

Houve aumento da população de protozoários totais com a inclusão do FM, e este comportamento pode ser explicado pelo aumento do $\mathrm{pH}$ do rúmen, que tornou este ambiente mais adequado ao metabolismo dos protozoários (Franzolin \& Dehority, 1996).

\section{Conclusões}

1. As dietas com substituição de $45 \%$ do farelo de soja por farelo de mamona destoxificado favorece o ambiente ruminal dos ovinos.

2. As dietas com níveis de substituição de 15 , 30 , e $45 \%$ do farelo de soja pelo farelo de mamona destoxificado e sem substituição promovem teores de ureia séricos acima do intervalo fisiológico normal.

3. O farelo de mamona destoxificado não causa modificações das enzimas hepáticas dos ovinos submetidos às dietas.

4. Há incremento dos parâmetros ruminais influenciado pela substituição do farelo de soja pelo farelo de mamona destoxificado.

\section{Referências}

ANANDAN, S.; ANIL KUMAR, G.K.; GHOSH, J.; RAMACHANDRA, K.S. Effect of different physical and chemical treatments on detoxification of ricin in castor cake. Animal Feed Science and Technology, v.120, p.159-168, 2005

ARCURI, P.B.; LOPES, F.C.F.; CARNEIRO, J.C. Microbiologia do rúmen. In: BERCHIELLI, T.T.; PIRES, A.V.; OLIVEIRA, S.G. de. Nutrição dos ruminantes. Jaboticabal: Funep, 2006. p.111-140.

ASLANI, M.R.; MALEKI, M.; MOHRI, M.; SHARIFI, K.; NAJJAR-NEHAD, V.; AFSHARI, E. Castor bean (Ricinus communis) toxicosis in a sheep flock. Toxicon, v.49, p.400-406, 2007.

BARBOSA, J.D.; ÁVILA, S.C. de; DIAS, R.V. da C.; PFEIFER, I.B.; OLIVEIRA, C.M.C. de. Estudo comparativo de algumas provas funcionais do fluido ruminal e de metabólitos sanguíneos de bovinos e bubalinos. Pesquisa Veterinária Brasileira, v.23, p.33-37, 2003.

BATISTA, M. do C. de S.; CASTRO, R.S. de.; REGO, E.W.; CARVALHO, F.A. de; SILVA, S.M.M.S.; CARVALHO, C.C.D.; RIET-CORREA, F. Hemograma, proteinograma, ionograma e dosagens bioquímicas e enzimáticas de ovinos acometidos por conidiobolomicose no Nordeste do Brasil. Pesquisa Veterinária Brasileira, v.29, p.17-24, 2009.

BLAXTER, K.L.; CLAPPERTON, J.L. Prediction of the amount of methane produced by ruminants. British Journal of Nutrition, v.19, p.511-522, 1965.

BORGES, N.C.; SILVA, L.A.F.; FIORAVANTE, M.C.S.; CUNHA, P.H.J. da; MORAES, R.R.; GUIMARÃES, P.L.; MARTINS, M.E.P. Avaliação de suco ruminal de bovinos "a fresco" e após 12 horas de conservação. Ciência Animal Brasileira, v.3, p.57-63, 2002.

BRANCO, A.F.; MOURO, G.F.; HARMON, D.L.; RIGOLON, L.P.; ZEOULA, L.M.; MAIA, F.J.; CONEGLIAN, S.M. Fontes de proteína, ingestão de alimentos e fluxo esplâncnico de nutrientes em ovinos. Revista Brasileira de Zootecnia, v.33, p.444-452, 2004.

DEHORITY, B.A. Classification and morphology of rumen protozoa. Ohio: Wooster, 1977. 82p.

DEHORITY, B.A. Evaluation of subsampling and fixation procedures used for counting rumen protozoa. Applied and Environmental Microbiology, v.48, p.182-185, 1984.

FRANZOLIN, R.; DEHORITY, B.A. Effect of prolonged high-concentrate feeding on ruminal protozoa concentrations. Journal of Animal Science, v.74, p.2803-2809, 1996.

DIAZ GONZÁLEZ, F.H.; BARCELLOS, J.O.J.; OSPINAPATIÑO, H.O.; RIBEIRO, L.A.O. Perfil metabólico em ruminantes: seu uso em nutrição e doenças nutricionais. Porto Alegre: UFRGS, 2000. 108p.

HAAS-KOHN, L.J.G.; LUGNIER, A.-A.J.; TIBONI, O.; CIFERRI, O.; DIRHEIMER, G. Inhibition of Escherichia coli protein synthesis by a limited tryptic digest of ricin, the toxin of Ricinus communis L. seeds. Biochem. Biochemical and Biophysical Research Communications, v.97, p.962-967, 1980.

HUNTINGTON, G.B.; ARCHIBEQUE, S.L. Practical aspects of urea and ammonia metabolism in ruminants. Proceedings of the American Society of Animal Science, v.77, p.1-11, 1999.

KANEKO, J.J.; HARVEY, J.W.; BRUSS M. Clinical biochemistry of domestic animals. 5.ed. San Diego: Academic, 1997. 932p.

LABTEST. Sistema para diagnóstico: ureia. Belo Horizonte: Labtest, 1999.

LENG, R.A. Factors affecting the utilization of 'poor quality' forages by ruminants particularly under tropical conditions. Nutrition Research Reviews, v.3, p.277-303, 1990.

MARTINELE, I.; SIQUEIRA-CASTRO, I.C.V.; D'AGOSTO, M. Protozoários ciliados no rúmen de bovinos alimentados com dietas de capim-elefante e com dois níveis de concentrado. Revista Brasileira de Saúde e Produção Animal, v.9, p.74-81, 2008.

MENEZES, D.R.; ARAÚJO, G.G.L.; OLIVEIRA, R.L.; BAGALDO, A.R.; SILVA, T.M.; SANTOS, A.P. Balanço de nitrogênio e medida do teor de ureia no soro e na urina como monitores metabólicos de dietas contendo resíduo de uva de vitivinícolas para ovinos. Revista Brasileira de Saúde e Produção Animal, v.7, p.169-175, 2006. 
MERTENS, D.R. Creating a system for meeting the fiber requirements of dairy cows. Journal of Dairy Science, v.80, p.1463-1481, 1997.

NATIONAL RESEARCH COUNCIL. Nutrient requirements of small ruminants. Washington: NRC, 2007. 362p.

OLIVEIRA, A.S. de; CAMPOS, J.M.S.; OLIVEIRA, M.R.C.; BRITO, A.F.; VALADARES FILHO, S.C.; DETMANN, E.; VALADARES, R.F.D.; MACHADO, O.LT. Nutrient digestibility, nitrogen metabolism and hepatic function of sheep fed diets containing solvent or expeller castorseed meal treated with calcium hydroxide. Animal Feed Science and Technology, v.158, p.15-28, 2010 .

PRESTON, T.R. Biological and chemical analytical methods. In: PRESTON, T.R. (Ed.). Tropical animal feeding: a manual for research workers. Rome: FAO, 1995. p.191-264.

PUGH, D.G. Clínica de ovinos e caprinos. São Paulo: Roca, 2004. 528p.

RADOSTITS, O.M.; MAYHEW, I.G.J.; HOUSTON, D.M. Exame clínico e diagnóstico em veterinária. Rio de Janeiro: Guanabara Koogan, 2002. 591p.
ROSENBERGER, G. Exame clínico de bovinos. 3.ed. Rio de Janeiro: Guanabara Koogan, 1993. 420p.

SAS INSTITUTE. SAS/STAT user's guide. Version 9.1. Cary: SAS Institute, 2003.

SATTER, L.D.; SLYTER, L.L. Effect of ammonia concentration on rumen microbial protein production in vitro. British Journal of Nutrition, v.32, p.199-208, 1974.

SEVERINO, L.S. O que sabemos sobre a torta da mamona. Campina Grande: Embrapa Algodão, 2005. 31p. (Embrapa Algodão. Documentos, 134).

SILVA, D.J.; QUEIROZ, A.C. de. Análise de alimentos: métodos químicos e biológicos. 3.ed. Viçosa: UFV, 2002. 235p.

SNIFFEN, C.J.; O'CONNOR, J.D.; VAN SOEST, P.J.; FOX, D.G.; RUSSEL, J.B. A net carbohydrate and protein system for evaluating cattle diets: II. Carbohydrate and protein avalability. Journal of Animal Science, v.70, p.3562-3577, 1992.

VAN SOEST, P.J.; ROBERTSON, J.B.; LEWIS, B.A. Methods for dietary fiber, neutral detergent fiber, and nonstarch polysaccharides in relation to animal nutrition. Journal of Dairy Science, v.74, p.3583-3597, 1991.

Recebido em 5 de agosto de 2011 e aprovado em 7 de dezembro de 2011 